Otávio Roberto Jacobini ${ }^{1}$

Denise Helena Lombardo Ferreira ${ }^{2}$

Celso Ribeiro Campos ${ }^{3}$

Maria Lúcia Lorenzetti Wodewotzki ${ }^{4}$

\title{
A modelagem matemática como instrumento de interação entre aprendizagem curricular e reflexões críticas na sala de aula de estatística
}

Recebido em: 17/11/2012 - Aprovado em: 22/11/2012 - Disponibilizado em: 26/12/2012

\section{Resumo}

Neste artigo buscamos mostrar a associação entre aprendizagem curricular de conteúdos estatísticos e reflexões críticas decorrentes dos trabalhos investigativos intrínsecos aos cenários pedagógicos centrados na modelagem matemática. Inserimos este estudo no campo da Educação Estatística Crítica e após algumas considerações teóricas sobre a interface existente entre as competências estatísticas (a literacia, o pensamento e o raciocínio estatísticos) e a modelagem matemática, apresentamos um ambiente de modelagem matemática construído em uma sala de aula de Estatística. Com base nesse ambiente, mostramos a potencialidade pedagógica dos projetos de modelagem matemática, caracterizada de um lado, por contribuições do coletivo em benefício do processo de ensino e de aprendizagem, pela valorização da busca da informação, pela percepção do aluno da relevância da disciplina na sua formação intelectual e profissional, e pela compreensão da realidade ao seu redor. E, de outro lado, tal como preconizado por Skovsmose em seus trabalhos sobre a Educação Matemática Crítica, pelas valorizações da crítica e da criatividade do aluno (e, consequentemente, do seu crescimento político e social), e da contribuição dos projetos de modelagem para as reflexões intrínsecas a todos os momentos vivenciados por ele. Concluímos o artigo, refletindo sobre as possibilidades pedagógicas oferecidas pela associação dos assuntos inerentes aos temas dos projetos de modelagem com fatos discutidos pela

1 Otávio Roberto Jacobini é Doutor em Educação Matemática (UNESP/Rio Claro, 2001), é professor da Faculdade de Matemática do CEATEC/PUC-Campinas. Rod. D. Pedro I, Km 136 - Parque das Universidades, Campinas/SP - CEP 13086-900. e-mail:otavio@puc-campinas.edu.br

2 Denise Helena Lombardo Ferreira é Doutora em Educação Matemática (UNESP/Rio Claro, 2000), é professora da Faculdade de Matemática do CEATEC/PUC-Campinas. Rod. D. Pedro I, Km 136 - Parque das Universidades, Campinas/SP - CEP 13086-900. e-mail: lombardo@puc-campinas.edu.br.

3 Celso Ribeiro Campos é Doutor em Educação Matemática (UNESP/Rio Claro, 2007), é professor da FEA/PUC-SP, São Paulo, SP, Brasil, R. Monte Alegre, 894, Perdizes, São Paulo/SP - CEP 05014-901.e-mail: crcampos@pucsp.br.

4 Maria Lúcia Lorenzetti Wodewotzki é Livre docente em Estatística Aplicada à Educação (UNESP-Rio Claro, 1998), é professora da Pós Graduação em Educação Matemática, UNESP-Rio Claro. Av. 24A no.1515 - Bela Vista, Rio Claro/SP CEP 13506-900. Coordenadora do GPEE, Rio Claro, SP, Brasil. e-mail:mariallw@rc.unesp.br. 
imprensa, romanceados pela literatura e mostrados em filmes e em documentários.

Palavras-chave: Modelagem matemática. Conteúdos estatísticos. Educação estatística crítica. Críticas e reflexões.

\section{Abstract}

\begin{abstract}
In this article we have as purpose to show the association between learning curricular statistical content and critical reflections resulted from the investigative work closely related with the pedagogical scenarios focused on mathematical modeling. We insert this study in the field of Critical Statistics Education and after some theoretical considerations about the interface between statistical competencies (literacy, thinking and reasoning) and mathematical modeling, we present a mathematical modeling environment built on a Statistics classroom. Based on this environment we showed the pedagogical potential of mathematical modeling projects characterized on the one hand, by
\end{abstract}

\section{Introdução}

É crescente o número de pesquisas que abordam o ensino e a aprendizagem de conteúdos estatísticos na escola. Muitas dessas pesquisas mostram a importância do trabalho com projetos, com particular destaque à presença da modelagem matemática, nas aulas de Estatística (Campos; Wodewotzki; Jacobini, 2011; Mendonça; Lopes, 2010; Andrade, 2008) e, concomitantemente, do papel da mídia (jornais, revistas, televisão e Internet) como fonte de fornecimento pedagógico de contributions of the collective at benefiting the process of teaching and learning, by valorization of information searching, by students' perception of the importance of discipline in their intellectual and professional formation, and by understanding the reality around. And on the other hand, such as recommended by Skovsmose in his works on Critical Mathematics Education, regarding the valorization of criticism and creativity of the student (and hence their social and political growth), and the contribution of modeling projects to the reflections intrinsic to all experienced moments by them. We conclude the article reflecting on the pedagogical possibilities offered by the association of the issues inherent to the topics of modeling projects with facts discussed by the press, romanticized by literature and depicted in movies and documentaries.

Keywords: Mathematical modeling; Statistical contents; Critical statistics education; Reviews and reflections.

informações, verdadeiros conteúdos vivos presentes em nosso cotidiano. Essa fonte é formada de exemplos que envolvem gráficos e tabelas, de índices e de análises comparativas que requerem leitura dos mais variados tipos de dados. As informações disponíveis precisam ser analisadas e criticamente interpretadas, o que faz com que a presença da Estatística nas formações acadêmica e pessoal do estudante, de diferentes áreas e níveis escolares, seja cada vez mais valorizada.

Como constatam Batanero e Godino (2005), o papel da Estatística na sociedade moderna se destaca por prover ferramentas 
metodológicas para análise dos dados, para descrição e quantificação do relacionamento de variáveis, para o planejamento e análise de estudos e experimentos, para estimativas e tomada de decisões em situações de incerteza. Daí sua importância nos ambientes escolares.

Nessa direção, os Parâmetros Curriculares Nacionais, no Brasil, com a intenção de fornecer uma formação ampla e crítica ao estudante, destacam a importância do conhecimento de conteúdos estatísticos já nos níveis fundamental e médio. No ensino superior, além da relevância do conhecimento de conteúdos estatísticos nas ciências exatas, a sua importância está sendo igualmente reconhecida nas ciências sociais, nas ciências humanas e na área da saúde.

Se por um lado são indiscutíveis a importância e a necessidade da presença da Estatística na sala de aula, de outro lado é igualmente perceptível que há problemas pedagógicos em todos os níveis escolares, quer em relação ao ensino, quer em relação à aprendizagem. E esses problemas são responsáveis por muitas das dificuldades enfrentadas pelos alunos em suas atividades curriculares. Como explicado em Campos, Wodewotzki e Jacobini (2011), essas dificuldades pedagógicas têm incentivado pesquisadores a buscar suas origens, dando início assim a essa nova área de atuação pedagógica denominada Educação Estatística (EE). Investigar essas dificuldades e buscar procedimentos pedagógicos para superá-las tem sido o principal objetivo do nosso grupo de pesquisa (GPEE - Grupo de Pesquisa em Educação Estatística da UNESP de Rio Claro).
A EE, como campo de ação, extrapola as preocupações com dificuldades pedagógicas (de aprender e de ensinar) e concentra seu interesse no desenvolvimento de uma postura investigativa, reflexiva e crítica do aluno em uma sociedade globalizada (e desigual), marcada pelo acúmulo de informações e pela necessidade de tomada de decisões em situações de incerteza. Nesse contexto, a EE tem mostrado que a eficiência do ensino e da aprendizagem dos conteúdos de Estatística está fortemente associada com o desenvolvimento de três competências, relacionadas entre si: a literacia, o pensamento e o raciocínio estatísticos.

Essas competências, baseadas principalmente na interpretação e na compreensão críticas de informações provenientes de dados reais, estão associadas a uma educação voltada para a formação de uma cidadania crítica. Nessa linha, vemos o desenvolvimento dessas competências em harmonia com o pensamento pedagógico de Skovsmose (2008) que, focado na importância da formação de um estudante crítico, investigador, questionador e consciente dos problemas que afligem a sociedade, e com seu olhar voltado para as ideias de Paulo Freire, defende um ambiente pedagógico responsável pela promoção de uma educação problematizadora, dialógica e que estimule a criatividade e a reflexão do estudante.

Em nosso Grupo de Pesquisa inserimos a EE nesse ambiente idealizado por Skovsmose e, via de regra, nos baseamos nos princípios pedagógicos da modelagem matemática para trabalhar o ensino e a aprendizagem de Estatística por meio de 
projetos. Vemos essa conduta pedagógica como um instrumento de ação que possibilita ao aluno vivenciar situações nas quais ele tenha que avaliar resultados, questionar informações e desenvolver atitudes críticas e criativas. Agindo dessa forma, pensamos em um ambiente de aprendizagem que busca, no particular, favorecer o desenvolvimento de habilidades para lidar com os conceitos estatísticos no seu cotidiano e, no geral, contribuir fortemente para a formação de um cidadão crítico e consciente das suas obrigações sociais e políticas.

Temos defendido em nossos estudos um processo de ensino e de aprendizagem na perspectiva investigativa, no qual o aluno vivencia a geração e a análise de dados e, consequentemente, participa ativamente da construção do seu conhecimento. Outros trabalhos como os de Campos (2007) e Campos et al. (2011) têm esse mesmo propósito, defendendo o chamado learning by doing ou active learning, que traduzimos por aprender Estatística fazendo Estatística, e trazendo para a prática escolar os conceitos de Educação Estatística Crítica (EEC).

Buscamos, neste artigo, mostrar que é possível associar, por intermédio de projetos de modelagem matemática, as três competências que para nós formam o núcleo da $\mathrm{EE}$ - a literacia, o raciocínio e o pensamento estatísticos com o desenvolvimento do conhecimento curricular do aluno, com a valorização do s e u pensamento crítico e, consequentemente, com o seu crescimento político. Para tanto nos baseamos em um ambiente de modelagem matemática, construído em uma disciplina de Estatística, ministrada em um curso de
Administração. Em nossas conclusões fortalecemos essa associação com uma abordagem combinatória entre os resultados obtidos com os projetos de modelagem, com fatos discutidos pela imprensa, romanceados pela literatura e mostrados em filmes e documentários..

\section{Competências estatísticas e modelagem matemática}

O termo literacia nos remete à habilidade de ler, compreender, interpretar, analisar e avaliar textos escritos. A literacia estatística refere-se ao estudo de argumentos que usam a estatística como referência, ou seja, a habilidade de argumentar usando corretamente a terminologia estatística. Entendemos que a literacia estatística inclui também habilidades básicas e importantes que podem ser usadas para a compreensão de informações estatísticas. Essas habilidades incluem as capacidades de organizar dados, construir e apresentar tabelas e trabalhar com diferentes representações dos dados. A literacia estatística também inclui entendimentos de conceitos e de técnicas, de vocabulário, de símbolos e de probabilidade como medida de incerteza.

Essa visão de literacia tem sofrido variações, ao longo do tempo e, com o avanço da EE, diferentes autores foram introduzindo perspectivas mais abrangentes para essa competência. Rumsey (2002), em seus estudos, identifica os componentes da literacia, relacionando-a com a educação para a cidadania. Segundo a autora, para os alunos se tornarem bons cidadãos estatísticos, eles devem entender o suficiente para consumir as informações 
que permeiam nossa vida diariamente, sendo capaz de pensar criticamente sobre essas informações de modo a tomar decisões com base nelas.

O raciocínio estatístico é definido por Garfield (2002) como a maneira com a qual uma pessoa raciocina e se posiciona com base nas ideias e nas informações estatísticas. Isso engloba interpretações baseadas em conjuntos de dados e representações ou sumários estatísticos dos dados nas formas de gráficos e de tabelas. Em muitos casos o raciocínio estatístico envolve ideias de variabilidade, distribuição, chance, incerteza, aleatoriedade, probabilidade, amostragem e testes de hipóteses, o que leva a interpretações e inferências acerca dos resultados. O raciocínio estatístico pode ainda envolver a conexão de um conceito com outro (medidas centrais e variabilidade, por exemplo), ou pode combinar ideias sobre dados e chance. $\mathrm{O}$ raciocínio estatístico também incorpora o entendimento de um processo estatístico e as capacidades de interpretar os resultados obtidos de um problema baseado em dados reais e de explicá-los. Como diz Ben-zvi (2008), essas habilidades são importantes para o cotidiano dos cidadãos e devem, assim, constituir um ingrediente padrão na educação de todo estudante.

delMas (2004) afirma que o desenvolvimento do raciocínio estatístico deve configurar um objetivo explícito no ensino de Estatística. Para isso o autor diz que devem ser construídas atividades na sala de aula que extrapolam a aprendizagem de procedimentos e que buscam valorizar métodos que exijam dos estudantes um conhecimento mais profundo dos processos estocásticos.
Assim como Campos (2007) acreditamos que é possível ajudar os estudantes a desenvolver o raciocínio estatístico e, para tanto, certos procedimentos, como incentivos para a descrição verbal e escrita do processo estatístico que está sendo analisado, devem ser incorporados ao diaa-dia da sala de aula.

O pensamento estatístico, de acordo com Mallows (1998), pode ser entendido como a capacidade de relacionar dados quantitativos com situações concretas, admitindo a presença da variabilidade e da incerteza, explicitando o que os dados podem dizer sobre o problema em foco. O pensamento estatístico ocorre quando os modelos matemáticos são associados à natureza contextual do problema em questão, ou seja, quando surge a identificação da situação analisada e se faz uma escolha adequada das ferramentas estatísticas necessárias para sua descrição e interpretação.

Uma característica particular do pensamento estatístico é prover a habilidade de enxergar o processo de maneira global, com suas interações e seus porquês, entender suas diversas relações e o significado das variações, explorar os dados além do que os textos prescrevem e gerar questões e especulações não previstas inicialmente. O pensador estatístico, segundo Chance (2002), deve ser capaz de ir além do que lhe é ensinado no curso, de pesquisar, de refletir sobre o que está sendo investigado e de questionar espontaneamente.

Vemos a modelagem matemática como um importante instrumento de ação na sala de aula, capaz de tornar o ambiente pedagógico menos árduo para quem ensina e mais significativo para quem aprende. E, 
concomitantemente, de transformar a sala de aula em um cenário político, centrado em ações, atuações e participações dos atores (alunos e professor) na sociedade, no qual o professor tem a oportunidade de explorar possibilidades que possam contribuir para a formação crítica do estudante e para a construção da sua cidadania.

Ademais, como já dissemos em outro momento (Ferreira; Jacobini, 2009, 2010), a modelagem matemática, além de ser um importante instrumento de aplicação da matemática para resolver problemas reais, também gera necessidades para o levantamento de dados e para simplificações das situações da realidade. Nessa direção, a modelagem matemática contribui para a construção de um ambiente pedagógico no qual os alunos, de um lado, podem realizar simulações e fazer analogias na medida em que um mesmo modelo pode ser útil na representação de diferentes situações. E, de outro lado, eles podem identificar aplicações em outras áreas do conhecimento e em diferentes contextos, além de associar o conteúdo curricular com o mundo do trabalho.

Vemos, assim, o processo de modelagem com o seu início e com o seu término no mundo real, passando por investigações e por reflexões que fundamentem a construção ou a escolha de modelos matemáticos, pelas etapas de validação e de interpretação de resultados, e pela sistematização do conteúdo. Além disso, esse processo de modelagem deve envolver igualmente investigações não matemáticas e discussões, chamadas paralelas por Barbosa (2007), que envolvem, dentre outras, as percepções sobre a realidade social na aula de matemática e o uso do conhecimento matemático para legitimar os discursos que analisam as questões da vida na sociedade (contexto social e cultural).

A modelagem matemática, quando aplicada no ensino de Estatística, permite a construção de ambientes pedagógicos que possibilitam ao aluno vivenciar a aplicabilidade dos conteúdos estatísticos e, ao mesmo tempo, desenvolver as capacidades de pesquisar, de realizar trabalhos em grupo, de discutir, de refletir, de criticar e de comunicar suas opiniões. A incorporação dos princípios pedagógicos da modelagem matemática aos procedimentos didáticos da Estatística, operacionalizada pelo trabalho com projetos, mostra-se relevante justamente por incentivar e contribuir para $o$ desenvolvimento das capacidades de literacia, raciocínio e pensamento estatísticos.

Avaliamos no nosso grupo de pesquisa que essa relevância evidencia-se com mais intensidade se no cenário pedagógico centrado na modelagem matemática forem valorizados trabalhos com dados reais (realizados preferencialmente em grupos), relacionamentos desses dados com $\mathrm{o}$ contexto em que eles estão inseridos, recomendações para interpretações dos resultados conseguidos, e incentivos tanto para a construção de ambientes na sala de aula voltados para críticas, discussões e reflexões, quanto para o compartilhamento com a comunidade (a própria escola ou o meio no qual a escola está inserida) dos resultados obtidos com os trabalhos realizados. É com nosso olhar atento nessas valorizações que buscamos interagir aprendizagem curricular e reflexões críticas. Essa interação que aqui 
abordamos baseia-se em um cenário pedagógico que construímos em uma sala de aula de Estatística e que valoriza a EEC na medida em que, conforme Campos et al. (2011), promove uma educação problematizadora, dialógica, criativa e reflexiva; estimula a inserção crítica do estudante na realidade em que ele vive; incorpora os aspectos políticos envolvidos no processo educativo; incentiva o trabalho em grupo e colaborativo; proporciona o desenvolvimento de relacionamentos sociais; combate as posturas alienantes dos alunos e defende a ética e a justiça social.

\section{A modelagem matemática como instrumento de interação entre aprendizagem curricular e reflexões críticas na salla de aula de Estatística}

Para essa abordagem nos baseamos em um ambiente pedagógico, centrado em projetos de modelagem matemática, construído pela professora da disciplina de Estatística de um curso de graduação em Administração (segunda autora deste trabalho) e que contou com a participação de uma mestranda em Educação Matemática na UNESP (Rio Claro/SP, Brasil). O projeto foi desenvolvido durante o $1^{\circ}$ s e m e stre de 2010 e o acompanhamento e a análise das atividades realizadas resultaram na elaboração da dissertação, intitulada "Educação Estatístic a Crítica: u ma possibilidade?" (SAMPAIO, 2010). As atividades desenvolvidas no ambiente de aprendizagem foram acompanhadas pelo
GPEE - Grupo de Pesquisa em Educação Estatística da UNESP de Rio Claro. ${ }^{5}$

Para o desenvolvimento desses projetos foram feitas as seguintes escolhas:

- Trabalhos realizados em grupo com liberdade para suas organizações.

- Temas dos projetos escolhidos pelos alunos com as participações da professora da disciplina e da mestranda que acompanhou o trabalho.

- Atividades dos grupos realizadas tanto na sala de aula quanto fora do horário escolar.

- Abordagem na sala de aula dos conteúdos estatísticos necessários para os trabalhos.

No início do curso, com uma exposição preliminar, a professora da disciplina procurou mostrar aos alunos que as atividades relacionadas com seus trabalhos contribuiriam para a vivência de um processo de investigação estatística em um ambiente de modelagem matemática, para a percepção da aplicabilidade de certos conteúdos curriculares estatísticos em problemas reais e para a compreensão de aspectos importantes inerentes aos seus temas de trabalho. A professora também informou que cada grupo deveria realizar uma pesquisa de opinião com questões relacionadas com o assunto escolhido, além de obter informações especificas sobre ele em fontes apropriadas (livros, filmes, jornais, revistas, Internet, etc.), elaborar um relatório com os resultados obtidos e discutir esses resultados com

\footnotetext{
${ }^{5}$ Resultados extraídos deste cenário também foram analisados no trabalho "O ensino e a aprendizagem de conteúdos estatísticos por meio de projetos", apresentado pelos autores na VIII CIAEM - Conferência Interamericana de Educação Matemática, em 2011 (FERREIRA et al., 2011).
} 
seus pares dentro dos grupos e em sala de aula. Esses projetos fariam parte do processo de avaliação.

Para o desenvolvimento de suas atividades os grupos receberam algumas recomendações:

- A escolha do tema de trabalho deveria estar acompanhada da respectiva justificativa.

- Os objetivos do trabalho deveriam ser explicitados.

- Para a pesquisa de opinião sobre o tema, o questionário para a coleta de dados precisaria conter no mínimo três variáveis qualitativas e três quantitativas.

- Os cruzamentos entre as variáveis envolvidas na pesquisa e os seus respectivos gráficos, bem como a obtenção de medidas estatísticas das variáveis numéricas (tais como média, moda e mediana, estudo da simetria, desvio padrão e coeficiente de variação) eram imprescindíveis.

- Algumas dessas variáveis quantitativas deveriam conter estudos sobre correlação e mostradas pelos gráficos de dispersão contendo a reta de regressão e o coeficiente de determinação.

Os relatórios dos projetos deveriam obedecer a seguinte estrutura: introdução; apresentação dos dados; análise, discussão e interpretação dos resultados; comparação desses resultados com os de outras pesquisas publicados na mídia (Internet, jornais e revistas); conclusões e comentários finais; referências bibliográficas.
Depois de algumas orientações sobre procedimentos, discussões em sala de aula e superação das principais dificuldades, os seguintes temas de trabalho foram escolhidos pelos grupos: Alimentação dos estudantes; Bebidas; $O$ uso do computador; Futebol e Sociedade; Meios de Informação; McDonald's; Preocupação com a saúde; Qualidade no transporte público na cidade de Campinas; Viagens; Avaliando o nível da alimentação. Após a escolha dos seus temas os grupos definiram quais variáveis deveriam constar dos questionários que seriam aplicados aos entrevistados. Essa definição de variáveis é relevante em projetos que envolvem questionários estatísticos na medida em que a análise dos dados em pesquisas de opinião é feita com base nos resultados apresentados por elas e pelos seus relacionamentos. Algumas variáveis como gênero, idade, renda e escolaridade fizeram parte de todos os questionários. As entrevistas para a obtenção dos dados foram realizadas pessoalmente, por telefone, ou por e-mail. As amostras, convenientes e não aleatórias, foram escolhidas pela facilidade de acesso dos grupos aos entrevistados. Por essa razão os resultados encontrados foram trabalhados exclusivamente para a abordagem de conteúdos curriculares de Estatística e para a construção de ambientes favoráveis para discussões e reflexões críticas. E, como explicamos aos alunos, esses resultados não poderia ser inferidos para a população.

\section{Aprendizagem curricular reflexões críticas}

Como dissemos anteriormente, mantendo nosso olhar pedagógico nos 
princípios filosóficos da Educação Matemática Crítica e em consonância com os fundamentos da Educação Estatística, centramos nossa atenção tanto na formação acadêmica do estudante quanto no seu crescimento político e social.

Os projetos desenvolvidos pelos alunos mostraram-se adequados para investigações estatísticas, voltadas para o desenvolvimento do conteúdo curricular da disciplina, e para investigações não estatísticas relacionadas com situações inerentes aos assuntos que estavam sendo investigados. Essa combinação entre as investigações estatísticas e as não estatísticas fica evidenciada nos relatórios elaborados pelos grupos, mormente nas análises apresentadas por eles, quer em relação às variáveis individuais, quer em relação aos relacionamentos entre elas.

Em trabalhos anteriores realizados no nosso grupo de pesquisa mostramos que a combinação desses dois modelos de investigação contribui tanto para a compreensão de importantes aspectos que envolvem os temas de trabalho quanto para a formação acadêmica e para o desenvolvimento do pensamento crítico e reflexivo do estudante. Essa combinação, no âmbito da Educação Matemática, é abordada por Jacobini (2011), e é também percebida por Sampaio (2010) que, com base nas ponderações de Barbosa (2007) e com seu olhar voltado para a Educação Estatística, destaca a natureza das discussões surgidas no ambiente da sala de aula e as classifica em Matemáticas, Técnicas, Reflexivas e Paralelas.

Com o enfoque no conteúdo programático da disciplina buscamos conduzir as atividades de modo que elas propiciassem a aprendizagem de conceitos relacionados com a Estatística Descritiva (tabelas, gráficos, resumos numéricos de medidas, linhas de tendência, correlação). Aproveitamos para introduzir assuntos não previstos no programa da disciplina (amostragem, margem de erro, nível de confiança e tamanho da amostra), mas que eram necessários para a compreensão de alguns princípios de inferência. Para facilitar a percepção desses assuntos e das relações entre eles, organizamos uma atividade relacionada com a simulação de resultados amostrais com base em um parâmetro conhecido (no caso, o resultado da eleição presidencial de 2010). Essa atividade foi desenvolvida no Laboratório de Informática. Também no Laboratório de Informática trabalhamos com a Tabela Dinâmica do Excel e com O EstatD $+{ }^{6}$ para a organização e apresentação dos dados por meio de tabelas e de gráficos e para a geração dos resumos estatísticos, da reta de regressão e do coeficiente de determinação das variáveis numéricas.

Os resultados obtidos com base na análise das variáveis e dos cruzamentos entre elas, mostrados nos relatórios apresentados pelos grupos, propiciaram discussões e reflexões entre os seus integrantes e debates na sala de aula. Alguns desses resultados, mesmo não tendo havido a priori formulação de hipóteses, confirmaram o que já era esperado. Outros deles, entretanto, foram surpreendentes, já que não coincidiam com o que se imaginava encontrar, como foi o caso do resultado encontrado pelo grupo responsável pelo tema Alimentação dos estudantes que, ao analisar o cruzamento

${ }^{6} \mathrm{O}$ EstatD+ é um software de domínio público e está disponível em: www.calculo.iq.unesp.br/estatistica.html. 
da variável "quem é responsável pelo preparo da refeição na sua casa" versus a variável "Gênero", concluiu que, diferentemente do que se pensava, $41 \%$ dos respondentes masculinos disseram ser eles mesmos os responsáveis pelo preparo de sua própria comida (contra apenas 36\% das mulheres). Esses resultados trouxeram discussões entre os alunos e motivaram a busca de justificativas para tais porcentagens. Dentre essas justificativas destacaram-se as comparações entre as atividades profissionais da mulher nos dias de hoje, em contraste com o passado, quando a maioria delas se dedicava apenas aos afazeres domésticos e a criação de seus filhos.

Essas descobertas estatísticas, algumas conflitantes com o senso comum, despertaram o interesse dos alunos em confrontar seus resultados com aqueles que a mídia tem revelado sobre os temas e esse confronto serviu como pano de fundo para a discussão sobre a importância da compreensão da Estatística para a percepção crítica das informações divulgadas nos meios de comunicação. Diversos resultados, além de evidenciarem conflitos envolvendo índices, mostraramse igualmente polêmicos, motivaram críticas e propiciaram reflexões. O grupo responsável pelo tema Bebidas, por exemplo, ao analisar seus dados, constatou que aproximadamente $60 \%$ dos respondentes masculinos já haviam dirigido alcoolizados. Os alunos do grupo comentaram que esse desastroso resultado encontrado por eles contraria a chamada "lei seca", denominação popular dada a uma legislação que impõe severos limites ao consumo de álcool para quem dirige veículos automotores. Esse índice obtido pelo gênero masculino foi bastante contrastante com o apresentado pelo gênero feminino, já que apenas $22 \%$ das mulheres disseram ter dirigido após o consumo de algum tipo de bebida alcólica. Em seu relatório, e complementando suas análises a respeito desses índices, o grupo destacou que o consumo excessivo de bebidas alcoólicas é uma das principais causas de acidentes de trânsito.

No debate relacionado com esse tema e ocorrido na sala de aula os alunos comentaram sobre o bar localizado nas proximidades da Universidade, o que dá a impressão de que ele é uma extensão da instituição. Ademais, os estudantes, criticando o Poder Público que permite tal proximidade, disseram que essa localização possibilita que muitos alunos troquem a sala de aula pelo bar, e lá, além de gastar dinheiro, acabam bebendo e fumando. Na maioria das vezes são jovens que não têm ideia do prejuízo que esses vícios trazem à sua saúde e que ignoram o perigo de dirigir alcoolizado, com riscos a si próprios e à vida de pessoas inocentes. Os alunos concluíram que as leis deveriam ser mais severas, regulando tanto a venda quanto o consumo de bebidas alcoólicas, principalmente em locais próximos de instituições escolares.

A descoberta de que conhecimentos de informática eram maiores entre as mulheres do que entre os homens, obtida pelo grupo responsável pelo tema $O$ uso do computador, trouxe a tona o debate sobre a ampliação da presença feminina em todos os setores da sociedade. Se por um lado, e como já era esperado, "pérolas" negativas, como frases que diziam que "os homens apenas estavam dando oportunidade às mulheres" ou que os "homens eram 
responsáveis pelo raciocínio e as mulheres pela execução" foram mencionadas, por outro lado os resultados confirmavam que a presença feminina no mercado de trabalho acentua-se neste início de século 21, principalmente em setores que, em épocas anteriores, eram exclusivamente de responsabilidade dos homens. Exemplos de mulheres que conquistaram sucesso em suas carreiras, assumindo importantes funções tanto em empresas privadas como públicas, foram trazidos para o debate na sala de aula.

Significativas polêmicas surgiram com os resultados apresentados pelo grupo responsável pelo tema Futebol $e$ Sociedade. Naturalmente resultados já esperados e que fazem parte do conhecimento geral foram apresentados pelo grupo, como principalmente aqueles que mostravam que os homens têm bem mais interesse pelo futebol do que as mulheres. Entretanto, em relação ao futebol feminino, surpreendentemente, os resultados mostraram que os homens têm mais interesse no seu desenvolvimento do que as próprias mulheres. Esses índices, mesmo não podendo ser inferidos para a população, contribuem para justificar a fraca presença do futebol feminino brasileiro no cenário mundial, em contraste com o sucesso alcançado pelos futebolistas masculinos.

O cruzamento entre as variáveis "Renda" e "Origem do produto adquirido (oficial ou pirata)" indicou que a maioria dos consumidores de produtos oficiais de clubes (camisas, bonés, etc.) é formada de pessoas provenientes das camadas mais pobres da sociedade. Esse resultado, apesar de bastante questionável, indica que, possivelmente, pessoas com menor poder aquisitivo preferem comprar produtos que rendem recursos financeiros para seus clubes, em contraste com aquelas mais ricas, que parecem não ter essa preocupação.

Talvez essa opção, na medida em que produtos piratas relacionados com clubes esportivos são fartamente oferecidos, seja justificada pela apaixonante identificação das pessoas dessa camada da sociedade com seus times de futebol. A possibilidade de que pessoas com níveis de escolaridade mais altos (como esperado entre os mais ricos) nem sempre fazem uso de seus conhecimentos para agirem corretamente, também foi levantada no debate entre os alunos.

Como mostra Sampaio (2010), o grupo também comparou seus dados com os resultados apresentados por recente pesquisa sobre a popularidade dos diversos times brasileiros, realizada pelo instituto DataFolha e, simultaneamente com essa comparação, fez uma análise crítica tanto do trabalho que eles realizaram (amostragem deficiente, estratificação, etc.) quanto da pesquisa realizada pelo instituto ligado ao Jornal Folha de S. Paulo.

Nos trabalhos realizados pelos grupos, as três competências estatísticas (literacia, pensamento e raciocínio) foram valorizadas na medida em que os alunos trabalharam com dados reais, obtidos por eles próprios nas entrevistas que realizaram; relacionaram seus dados e seus resultados ao contexto em que eles estavam inseridos e os compararam com aqueles que estavam sendo apresentados pela mídia; interpretaram seus resultados e elaboraram relatórios escritos; debateram com seus pares de grupo e com seus 
colegas de classe seus resultados e suas descobertas; participaram de uma atividade prática (no Laboratório de Informática), na qual puderam realizar experimentações de amostragem e, assim, verificar que seus resultados, obtidos de forma conveniente, não poderiam ser generalizados.

Especialmente em relação à literacia estatística, ela foi estimulada na medida em que os alunos aprenderam conceitos estatísticos e souberam relacioná-los com seus dados e usar a Estatística como referência em seus argumentos, organizando os dados obtidos, construindo tabelas e gráficos, e obtendo informações quantitativas. Além disso, eles discutiram criticamente as informações veiculadas pela mídia, mormente aquelas que estavam relacionadas com seus temas.

O raciocínio estatístico foi valorizado no momento em que os alunos, com seus projetos de modelagem, puderam vivenciar um processo estatístico e precisaram explicá-lo aos seus colegas. Além disso, os estudantes interpretaram estatisticamente os resultados encontrados e, para essa interpretação eles precisaram fazer diversas conexões entre os dados e os conceitos estatísticos estudados no curso, como, por exemplo, aqueles relacionados com medidas de centro e dispersão, variáveis e correlação.

Por fim, quanto ao pensamento estatístico percebemos avanços na medida em que os alunos, de um lado, souberam relacionar os dados quantitativos com situações concretas, associar os modelos matemáticos utilizados com o contexto do problema, e identificar as ferramentas estatísticas adequadas (medidas de posição e dispersão, variáveis qualitativas e quantitativas, coeficiente de correlação, etc.) para a descrição e interpretação dos resultados de suas pesquisas. E, de outro lado, conseguiram utilizar criticamente seus resultados, como mostraram os casos acima apresentados.

Assim, essa junção das três competências no ambiente pedagógico construído com base nos projetos de modelagem, tal como preconizado por Skovsmose (2008), contribuiu para valorizar um processo educacional problematizador, dialógico e estimulante para a crítica e para a criatividade do aluno, tanto em relação à aprendizagem curricular quanto em relação à sua aplicabilidade no trabalho prático e à sua contribuição para as reflexões intrínsecas a todos os momentos vivenciados por eles. Além disso, o ambiente construído auxiliou os alunos na compreensão das limitações dos conteúdos que aprenderam, na observação das diferentes dimensões entre a teoria e a prática. Ademais, eles se sentiram valorizados ao expor suas ideias e incertezas, o que propiciou uma rica troca de experiências.

\section{Interação entre aprendizagem curricular e reflexões críticas nas a ulas de estatística: novas possibilidades e perspectivas}

Neste artigo buscamos mostrar a associação entre aprendizagem curricular de conteúdos estatísticos e reflexões críticas decorrentes dos trabalhos investigativos intrínsecos aos cenários pedagógicos centrados na modelagem matemática. Em um ambiente investigativo na sala de aula, aprendizagem curricular e conhecimento sobre o que envolve o objeto do ensino entrelaçam-se e se relacionam. 
Não são estanques, nem paralelos e muitos menos separados um do outro, independentemente da disciplina e da pedagogia.

Agora, em nossas considerações finais, e com a intenção de ampliar tanto a perspectiva investigativa quanto os meios para a construção de cenários apropriados para a valorização de discussões na sala de aula, concentramos nossa atenção nas possibilidades pedagógicas oferecidas pela associação dos assuntos inerentes aos temas dos projetos de modelagem com fatos discutidos pela imprensa, romanceados pela literatura e mostrados em filmes e em documentários.

Vemos este modelo de ambiente de investigação, construído com base na integração entre o pedagógico e o cotidiano discutido na mídia, como uma forma de educação voltada para a responsabilidade social que busca contribuir tanto para o enriquecimento cultural e científico do estudante quanto para a sua formação crítica expressa pelo seu crescimento político-social e pelo seu amadurecimento enquanto cidadão presente em uma sociedade que, concomitantemente com uma expressiva riqueza de consumo e com uma forte presença tecnológica, convive com enormes desigualdades sociais.

$\mathrm{Na}$ discussão sobre a ampliação da presença feminina no mercado de trabalho, investigações mais aprofundadas mostrariam exemplos de mulheres que conquistaram sucesso em suas carreiras, assumindo importantes funções tanto em empresas privadas como públicas. Confirmam esses exemplos as funções políticas de extrema responsabilidade exercidas por Dilma Roussef, Angela
Merkel e Cristina Kirchner, chefes de governo respectivamente do Brasil, Alemanha e Argentina, e de Michelle Bachelet, eleita e reeleita para governar o Chile após longo período de ditadura militar. Reforça a ampliação feminina na responsabilidade pela condução política do Brasil a significativa presença das mulheres na chefia de diversos ministérios e órgão públicos, na Câmara Federal e no Senado da República, além do Supremo Tribunal Federal. Na política mundial, destacam-se a figura marcante de Hillary Clinton como Secretária de Estado dos Estados Unidos, função quase tão importante quanto aquela do presidente do país, sucedendo a também mulher Condoleezza Rice, e Christine Lagarde, primeira mulher a dirigir o Fundo Monetário Internacional (FMI). O caso de Patrícia Melo, comandante de avião, é outro exemplo do sucesso feminino em campos profissionais amplamente dominados pelos homens.

Fatos associados ao consumo de bebida alcoólica, trazidos pela mídia e relacionados com graves acidentes automobilísticos, com exemplos negativos de personalidades pegas em batidas policiais, e com casos de doenças graves e de mortes precoces, mostrariam novas possibilidades ao trabalho apresentado pelo grupo responsável pelo tema Bebidas. Filmes e livros que mostraram a decadência de importantes ídolos mundiais colaborariam significativamente com essas novas possibilidades. O filme "Edith Piaf um hino ao amor", produzido em 2007 e dirigido por Olivier Dahan, por exemplo, mostra a ascensão e a queda de uma das maiores artistas francesas, destruída pela bebida e, como decorrência, pelas drogas. Mais recentemente, a película dirigida por 
José Henrique Fonseca sobre a vida de Heleno de Freitas, cuja figura foi brilhantemente interpretada por Rodrigo Santoro, conta a trajetória de um dos maiores ídolos futebolísticos do passado, morto em um sanatório aos 39 anos de idade. Na literatura, Ruy Castro mostra o lado triste da vida do grande Garrincha, atleta que tinha tudo em suas mãos, mas acabou destruído pela bebida (CASTRO, 1995). Situações similares às de Garrincha são vividas nos dias de hoje por inúmeros jogadores e ex-jogadores de futebol.

Como abordado em Jacobini (2011), e especificamente sobre o futebol, outros caminhos poderiam ser explorados. O papel da mídia no endeusamento e na destruição de atletas é um deles. Investigações sobre o tema na literatura, no cinema e até mesmo na academia também proporcionariam novos encaminhamentos ao debate. Algumas histórias publicadas versam sobre proezas e encantamentos, como as escritas sobre Pelé, considerado o melhor jogador de futebol de todos os tempos. Mas muitos outros, com enredos nem sempre repletos de glamour (como a vida de Heleno de Freitas e o livro de Ruy Castro), contém fatos e verdades sobre dificuldades enfrentadas pela maioria dos atletas, principalmente nos momentos de despedida dos campos. Inúmeros documentários e diversos trabalhos acadêmicos têm sido produzidos sobre situações envolvendo o mundo da bola, o futebol e seus ídolos, as paixões populares que envolvem esse esporte, as fanáticas torcidas pelos times de futebol (e algumas trágicas consequências desse fanatismo) e a vida de atletas e de ex-atletas.

No cinema, e igualmente como apontado em Jacobini (2011), os dois filmes dirigidos por Ugo Giorgetti são fontes obrigatórias de investigação sobre $o$ tema. O primeiro deles ("Boleiros - era uma vez o futebol", realizado em 1998) retrata a vida futebolística, mostrando um grupo de ex-jogadores que se reúnem quase todas as tardes para relembrar antigas glórias do passado. Depois, na continuação com "Boleiros - vencedores e vencidos", realizado em 2006, a abordagem se volta para o grande negócio envolvendo transações de jogadores para países da Europa. Já o filme "Linha de Passe", dirigido por Walter Salles e Daniela Thomas, aborda o sonho de um jovem de periferia em se tornar atleta de um grande time, mas que vê suas chances se reduzirem com o avançar da idade. Para conseguir seu objetivo, estratégias nem sempre éticas e às vezes ilegais são utilizadas. Dentre elas o filme aborda a alteração da data de nascimento e o pagamento de propina para empresários do mundo da bola.

Concluímos reafirmando que os caminhos que se abrem com a opção pela modelagem matemática na sala de aula, baseada em temas contemporâneos e do interesse da comunidade e, na sequência, pela valorização do papel da mídia como importante agente pedagógico e de fonte de informação, apontam para a inserção desse modelo pedagógico nas aulas de Estatística em um contexto fortemente identificado com a Educação Estatística Crítica. Assumimos esse modelo com a intenção de ampliar o horizonte do estudante, quer em relação ao conteúdo programático, quer em relação aos fatos inerentes às temáticas abordadas nos projetos. Consideramos esse modelo como um instrumento político capaz de conduzir o estudante à compreensão de aspectos 
importantes relacionados com essas temáticas e, consequentemente, de contribuir no sentido de torná-lo mais sensível para refletir sobre esses aspectos, de modo que o seu julgamento sobre eles seja organizado conscientemente, independentemente dos chamados "formadores de opinião".

\section{Referências Bibliográficas}

ANDRADE, M. M. Ensino e aprendizagem de Estatística por meio da modelagem matemática: uma investigação com o ensino médio. 2008. 193f. Dissertação (Mestrado em Educação Matemática) Instituto de Geociências e Ciências Exatas, Universidade Estadual Paulista, Rio Claro, 2008.

BARBOSA, J. C. Mathematical modelling and parallel discussions. In: 5th Congress of the Europen Society for Research in Mathematics Education, 2007, Larnaca. Proceedings of the 5th CERME, v. 1, 2007, p. 1-10.

BATANERO, C.; GODINO, J. Perspectivas de la educación estadística como área de investigación. In: LUENGO, R. (Ed.). Lineas de investigación en Didáctica de las Matemáticas. Badajoz: Universidad de Extremadura, 2005, p. 203-226.

BEN-ZVI, D.Research on Developing Statistical Reasoning: Reflections, Lessons Learned, and Challenges. ICME 11 Annals. Monterrey, México, 2008. Disponível em: <http:// icme11.org/node/1530>. Acesso em: 24/abr/2010.

CAMPOS, C. R. A Educação Estatística: uma investigação acerca dos aspectos relevantes à didática da estatística em cursos de graduação. Tese (doutorado em Educação Matemática), 242 f. Rio Claro/SP: UNESP-IGCE, 2007.

CAMPOS, C. R.; JACOBINI; O. R.; WODEWOTZKI, M. L. L.; FERREIRA, D. H. L. Educação Estatística no contexto da Educação Crítica. In: Boletim de Educação Matemática (BOLEMA). V. 24, n. 39, pp. 473-494. Rio Claro/SP: UNESP-IGCE, 2011.

CAMPOS, C. R.; WODEWOTZKI, M. L. L.; JACOBINI, O. R. Educação Estatística teoria e prática em ambientes de modelagem matemática. Belo Horizonte: Autêntica, 2011. CASTRO, R. Estrela solitária: um brasileiro chamado Garrincha. Rio de Janeiro: Companhia das Letras. 1995. 
CHANCE, B. L. Components of statistical thinking and implications for instruction and assessment. In: Journal of Statistics Education, v. 10, n. 3, 2002. Disponível em: <http:// www.amstat.org/publications/jse/v10n3/chance.html>. Acesso em: 14/jan/2011.

DELMAS, R. A comparison of mathematical and statistical reasoning. In: BEN-ZVI, D.; GARFIELD, J. (Eds.), The Challenge of Developing Statistical Literacy, Reasoning, and Thinking, 79-95. Dordrecht, The Netherlands: Kluwer Academic Publishers, 2004.

FERREIRA, D. H. L.; JACOBINI, O. R. Mathematical modelling: from classroom to the real world. In: BLOMHOJ, M.; CARREIRA, S. (orgs.). Mahtematical applications and modelling in the teaching and learning of mathematics. IMFUFA tekst, n. 461, 35-46, 2009.

FERREIRA, D. H. L.; JACOBINI, O. R. Ambiente de trabalho e Modelagem Matemática. Anais da VI Conferência sobre Modelagem na Educação Matemática. Londrina - Paraná, 2010.

FERREIRA, D. H. L.; JACOBINI, O. R.; CAMPOS, C. R.; WODEWOTZKI, M. L. L. O ensino e a aprendizagem de conteúdos estatísticos por meio de projetos. Anais da XIII Conferência Interamericana de Educação Matemática, Recife, 2011.

GARFIELD, J. The challenge of developing statistical reasoning. Journal of Statistics Education, v. 10, n. 3, 2002. Disponível em: <http://www.amstat.org/publications/jse/v10n3/ garfield.html>. Acesso em: 14/jan/2011.

JACOBINI, O. R. A modelagem matemática em ambientes de investigação nas aulas de Estatística: experiências pedagógicas no GPEE. Anais da VII Conferência Nacional sobre Modelagem Matemática, Belém, 2011.

MALLOWS, C. The zeroth problem. The American Statistician, n. 52, p. 1-9, 1998.

MENDONÇA, L. O.; LOPES, C. E. O trabalho com Educação Estatística no ensino médio em um ambiente de modelagem matemática. In: LOPES, C. E.; COUTINHO, C. Q; ALMOULOUD, S (org.), Estudos e Reflexões em Educação Estatística. Campinas: Mercado de Letras, 2010, p. 157-172.

RUMSEY, D. J. Statistical literacy as a goal for introductory statistics courses. Journal of Statistics Education, v. 10, n. 3, 2002. Disponível em: <http://www.amstat.org/publications/ jse/v10n3/rumsey2.html>. Acesso em: 14/jan/2011. 
SAMPAIO, L. O. A Educação Estatística Crítica: uma possibilidade?. 2010, $108 \mathrm{f}$. Dissertação (Mestrado em Educação Matemática) - Instituto de Geociências e Ciências Exatas, Universidade Estadual Paulista, Rio Claro, 2010.

SKOvSmOSE, O. Desafios da Reflexão em Educação Matemática Crítica. Campinas. Editora Papirus, 2008. 